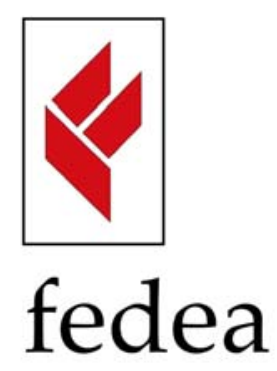

Fundación de

Estudios de

Economía Aplicada

Financial Analysts impact on Stock Volatility.

A Study on the Pharmaceutical Sector

by

Clara I. Gonzalez*

Ricardo Gimeno ${ }^{* *}$

DOCUMENTO DE TRABAJO 2008-19

Serie Economía de la Salud y Hábitos de Vida

CÁTEDRA Fedea - la Caixa

May 2008

* $\quad$ FEDEA. cgonzalez@fedea.es

** Banco de España. ricardo.gimeno@bde.es

Los Documentos de Trabajo se distribuyen gratuitamente a las Universidades e Instituciones de Investigación que lo solicitan. No obstante están disponibles en texto completo a través de Internet: $h t t p: / / w w w . f e d e a . e s$.

These Working Paper are distributed free of charge to University Department and other Research Centres. They are also available through Internet: $h t t p: / / w w w . f e d e a . e s$.

ISSN:1696-750X 


\title{
Financial Analysts impact on Stock Volatility . A Study on the Pharmaceutical Sector ${ }^{1}$
}

\author{
Clara I. Gonzalez ${ }^{2, a}$, Ricardo Gimeno ${ }^{\text {b }}$ \\ ${ }^{a}$ FEDEA. Jorge Juan, 46. 28001 Madrid, Spain \\ ${ }^{\mathrm{b}}$ Banco de España. Alcalá 48. 28014 Madrid, Spain
}

\begin{abstract}
The arrival of new information helps financial markets to value assets, but it may has the side-effect of increasing their volatilities. A better knowledge of the mechanism that links relevant news and stock prices would help both private and institutional agents to improve the calibration of the risks implies in a given asset.

Financial analysts play a key role in distinguishing which news are relevant for the valuation of a particular asset, and the changes in their recommendations are signals of new information in the market.

This paper studies the impact those buy or sell recommendations have on returns and also on volatility instead of the traditional literature that focuses only on prices. The pharmaceutical companies in the New York Stock Exchange are especially suited for this type of analysis given the frequent discontinuities in their expected profits derived from the success or failure in the development of new drugs.

Twenty stocks are daily tracked for five years along with the recommendations given by financial analysts. We have modeled stock returns by a Markov Regime Switching model as in Schaller and van Norden (1997) and found two states of low and high volatilities. We have also found strong evidence that the probability of being in the estate of high volatility increases when a Financial Analyst changes his recommendation.
\end{abstract}

JEL CODES: G14, C22, L65

Key words: Financial analysts, news arrival, pharmaceutical companies, Markov Regime Switching model.

\footnotetext{
1 Acknowledgements: We would like to thank the helpful comments and suggestions from Jose Manuel Marqués, Helena Chuliá and those received in ASSET 2007, XV Foro de Finanzas 2007 and 32 Simposio de Análisis Económico 2007. The views in this paper are solely those of the authors.

2 E-mails: cgonzalez@fedea.es and ricardo.gimeno@bde.es
} 


\section{Introduction}

The aim of this paper is analyzing the impact on financial markets of the public recommendations given by Financial Analysts (FA). In this sense, the return and volatility of stocks are modeled by a Markov Regime Switching (MRS) Model, founding that transition probabilities between volatility regimes are dependent to changes in the recommendations of FA.

In a efficient market, share prices reflect the correct valuation with the available information. As a corollary, quote changes would be a consequence of the market reaction to the appearance of some relevant news. Unluckily, the identification of relevant news to the evaluation of the market is not straightforward. Although Fama et al. (1969) concluded that the information is quickly incorporated in the prices and it is not possible distinguish between the non expected part of the news from the expected one, several papers try to find the incidence of the arrival of news in returns. For example, Pearce and Roley (1985) analyzes the reaction of quotations to the announcements about monetary supply, inflation, economic activity and the discount rate. Through the expected part of the announcements is possible to test the Efficient Market Hypothesis (EMH) because only the surprise part of the announcement moves prices and in addition, the non-expected part related to monetary policy have a significant effect. So, the difficult point is to distinguish the anticipated part of an announcement (Pearce and Roley, 1985).

Castanias (1979) analyzes the variance in the previous days of an announcement because it could be an index of the proximity of a new information. In the same sense Ederington and Lee (1993) studies the impact of macroeconomic news, such as unemployment rates or several index prices and conclude that this data are the responsible of the most of market volatility. Through the analysis of this volatility is possible to obtain the speed of adjustment of the market to new information because high values of volatility will remain during later days.

Precisely, the role of FA is collecting all relevant information about an asset as well as evaluating its impact on the price, sending recommendations to the agents based. So, changes in FA assessments can be seen as a proxy of the entrance of new and relevant information to the market. They also act as amplifiers of any announcement, spreading their knowledge among actual and potential investors, and therefore affecting the behavior of the asset price. FA reports usually include the valuation of the asset, the emission of buy or sell recommendations, the forecasts about earnings or the emission of ratings or credit qualifications.

As stated by Womack (1996), the revision of the FA recommendation means 
that they have analyzed public available information and have reached the conclusion that the present price of the share is not correct. This author also finds a strong evidence that stock prices are significantly influenced by these changes in financial recommendations, not only in that moment but also in following months. Moreover, Womack (1996) concludes that the change associated to a buy recommendation is significant, but during a short period of time compared with a sell recommendation that can have impact during the six following months.

In fact, the companies englobed in the pharmaceutical and biotechnological sector in the United States are highly sensible to news and announcements such as the impact of the decisions about commercialization of a new medicine made by the Food and Drug Administration (FDA) because it could have serious effect on future cash flows. This feature makes them specially suited for the purpose of the present paper, where technical knowledge is needed for distinguishing the possibilities of new drug developments and their value for the company. Pharmaceutical sector has been studied through many points of view, most of them referred to aspects such as regulation (Danzon and Chao, 2000; Philipson, 2002) or about the financial valuation of patents (Grabowski and Vernon, 2002) or drug development costs, such as Grabowski and Vernon (1990); Berndt (2002); DiMasi et al. (2003). However, we cannot find so much literature that studies the pharmaceutical sector and its stock exchange characteristics. This paper contributes to the analysis of this particular industry in this aspect.

Nevertheless, measuring the impact of FA recommendations previously requires to impose some hypothesis about the stochastic model governing the behavior of both financial asset's returns and volatilities. In this sense, a mixture of two or more normal distributions is often enough to account for typical skewness and leptokurtosis on returns (Kon, 1984). If the arrival of new information to the market makes greater volatility than in the absence of news, then this behavior would be reflected in two different distributions, one with low variance for the moments of no news and another one with higher variance when announcements are made and markets react to new information.

Additionally, we have to take into account a number of stylized facts about volatility of financial asset prices such as volatility clustering, mean reverting and persistence that has been examined by many authors that have proposed different models such as the family of ARCH models (Engle, 1982; Bollerslev, 1986) or the large class of Markov-switching models introduced by Hamilton (1989, 1990). The regime-switching modeling approach was initially proposed as a characterization for economic and financial time series, in order to identify two separated regimes in business cycles. An extension of Hamilton's approach have been used to describe and analyze stock market returns in order to identify two regimes either in mean, variance or both. Some important papers that 
have used these technics to examine stock market returns are those of Turner et al. (1989); Hamilton and Susmel (1994); Schaller and van Norden (1997).

In the case of Turner et al. (1989), using S\&P monthly index data for the period 1946 - 1989, they consider a Markov switching model in which either the mean, the variance or both may differ between two regimes with univariate specifications with constant transition probabilities. Hamilton and Susmel (1994) propose a model with sudden discrete changes in the process that governs volatility. They find that a Markov switching model provides a better statistical fit to the data than ARCH models without switching. Schaller and van Norden (1997), in a result close to Turner et al. (1989), extend their approach in several aspects, i.e. examining whether stock market returns are predictable, even after accounting for Markov switching behavior, as well as whether the transition probabilities of the Markov chain vary over time in response to changes in economic variables. In particular, they look at whether the transition probabilities are influenced by the price/dividend ratio finding an asymmetric response to the past price/dividend ratio.

This paper has modeled stock returns by a Markov Regime Switching model as in Schaller and van Norden (1997) to twenty companies during five years along with the recommendations given by financial analysts. We have found two states of low and high volatilities and strong evidence that the probability of being in the estate of high volatility increases when a Financial Analyst changes his recommendation. Traditionally, literature has concentrated on the impact of FA recommendations on prices and the novelty is that we concentrate on the analysis of the impact of FA recommendations on volatility.

So, a MRS model would allow us to reproduce the main characteristics of stock returns, along with the identification of periods of low and high volatilities. The probabilities of being in each regime can be linked to the chances of appearance of new information in the market at an specific moment, and thereafter, FA recommendations would modify such probabilities.

The rest of the paper is organized as follows: in section 2 we describe the sector selected and the data collected for our analysis. In section 3, MRS models are estimated founding evidence of different volatility regimes. FA recommendation are added to the model in section 4 while section 5 concludes. 


\section{Data description}

\subsection{The pharmaceutical sector}

The pharmaceutical industry is a very dynamic sector because of its capacity to reinvent itself in the face of changing market models and government regulation. Currently, the industry is seeking to improve its results from the expected increasing demand that will suppose the ageing of the population, at the same time that increases its investments in research and development. In particular, the advances in genomic research could generate new therapeutic and diagnose products in the next few years. As part of this effort, the leading pharmaceutical companies are aggressively moving to form joint-ventures with small biotechnological companies to develop new generations of drugs.

Nowadays, the bulk of the benefits obtained by the industry is derived from a broad-based list of components used to treat infections, cardiovascular problems, depression or chronic diseases. Nevertheless, in recent years, the most important companies have also collaborated with small biotechnological companies to develop new therapeutic components based on the DNA technology and genomic research, with the objective to obtain new therapies for a variety of diseases.

Although these developments involve important challenges and strong investment in risky projects, the pharmaceutical industry is a healthy and profitable industry. A great share of the global pharmaceutical market is controlled by companies that are quoted in the New York Stock Exchange, making it an appropriate market to follow.

The product life cycle of nearly all medicines follows a stable and long term pattern. In the United States, after a period of twelve years on average of discovery, development, testing, and revision by the Food and Drug Administration (FDA), a branded drug will have a commercial life of about one decade (Grabowski and Vernon, 2002; Berndt, 2002), having an almost predictable path. In DiMasi et al. (2003) is evaluated the average cost of developing an innovative new drug at more than $\$ 800$ million, including expenditures on failed projects and the value of forgotten alternative investments. The process is similar both in Occidental Europe and Japan, the other two greater world areas where the discovery and development of new medicines take place (Standard \& Poor's, 2004).

The new medicines are discovered typically in scientific laboratories, where scientists look for new chemical substances or new uses for components already discovered. The process is long and laborious, and most of the attempts are unsuccessful. Before a medicine can be brought to the market, it must spend 
years of testing in order to receiving governmental approval. In the United States, this approval comes from the FDA and although other nations have their own equivalent agencies, they follow similar mechanisms and reach to similar approval decisions.

The process of the research of a new product is a difficult job in almost all the industries, but in this case the products come from the highly complex fields of molecular biology and the biochemistry. The discovery and development of new drugs is a very lengthy and costly process (DiMasi et al., 1991). Each possible drug has to pass through several phases that comprises studies in animals to studies in humans. Often, companies study hundreds of components before some of them can be identified as sufficiently safe to be able to carried out the studies in humans. Once completed the preclinical tests, the company must ask for before the FDA the opening of a file for the investigation of new medicines in humans (Investigational New Drug Application (IND)). If this is granted, the active principle is put under clinical tests in hospitals to demonstrate the security of the molecule.

Tests carried out in humans usually occur in three phases ${ }^{3}$ :

- Phase $I$ : the medicine is administrated to a relatively small number of healthy people to verify its safety. Small doses are provided at the beginning, if this test is satisfactory, the doses are increased in a progressive form to determine their safety at higher levels.

- Phase II: the drug is provided to patients who suffer the disease or condition that the medicine tries to treat. This second round of tests usually includes an larger population and usually is carried out during more time than the previous phase.

- Phase III: those substances that have passed phase I and II continue the process. At this level, more complex and rigorous tests are carried out in more numerous groups of ill patients to make sure the safety, efficacy and optimal doses of the medicine.

All the process can last about twelve years on average. The research in the pharmaceutical industry is characterized by being a very long process, dangerous in some way because few molecules will have success, very expensive and complex because of the importance of the personal, technology and research resources required. It is also a competitive market and must face continuously new paradigms and difficulties. Some figures show that through the several phases only one of 20 original substances may ultimately be approved for marketing (Standard \& Poor's, 2004).

All of these companies depend on the last decision from the FDA, and the

3 For more details Center of Drug Evaluation and Research (CDER) Handbook from Food and Drug Adminstration www.fda.gov/cder 
not approval in an intermediate phase involves the cost of a lot of economic resources that the company will have to assume. Once the FDA is next to announce its decision rumors and news appear and makes the price of the company in the stock exchange to vary depending on the expected news was good of bad. Financial analysts base their recommendations on the successes and failures of the company, given that the FDA approval of a new drug will suppose important profits that will ensure new cash-flows for the company, otherwise it will means the company will reduce its market share, when actual drug copyrights came to an end, and analyst can make a bad recommendation. All of these information will make that prices vary and it will be difficult to model its returns. And FA take into account all the information to elaborate their reports and they anticipate the information in their recommendations.

\subsection{Stock returns and volatilities}

The New York Stock Exchange defines companies to be part of the pharmaceutical industry if they are manufacturers of prescription or over-the-counter drugs, such as aspirin or cold remedies. On the other hand, biotechnological industry includes companies engaged in research and development of biological substances for drug discovery and diagnostic development, being their main revenue either the sale or licensing of these drugs and diagnostic tools.

Since 2004, this sector has its own index called NYSE Health Care Index. This index includes companies classified in the Health Care sector according to the Industry Classification Benchmark ${ }^{4}$. This is one of the three sectorial indexes that were created in January 2004, jointly with the NYSE Energy Index and the NYSE Financial Index.

Companies included in this index are pharmaceutical and biotechnological that have an important weight in the market capitalization of this sector. The market capitalization in January the 3rd, 2007 was 1962, 8 billion dollars, where the $72.2 \%$ has an American origin. The ten more important companies included in this Index in 31st July 2006 are presented in Table 1.

For the present paper we selected the pharmaceutical and biotechnological companies that quoted in the New York Stock Exchange in January of 2007, during the period 2001 to 2005.

4 The Industry Classification Benchmark is proprietary to FTSE International Limited and Dow Jones \& Company, Inc. and has been licensed for use by New York Stock Exchange. This classification - which comprises 10 industries, 18 supersectors, 39 sectors and 104 subsectors - provides accurate and globally accepted industry and sector classifications. 
Initially we obtained from NYSE/TAQ ${ }^{5}$ the closing quotations data and the corresponding negotiated volume of every share at every moment, for 36 pharmaceutical companies and 7 biotechnological companies. We have chosen those companies with a volume greater than 400,000 in order to assure they are liquid enough to be covered by a sufficient number of FA following the companies, and the prices correspond to efficiently-enough markets. Those companies that have passed a merger or acquisition process during the period $2001-2005$ have not been included in the sample (for example Sanofi-Aventis) because they have been under different situations and are difficult to isolate. After these filters we obtained a final sample of companies with 20 pharmaceuticals and 3 biotechnologicals (Table 2).

\subsection{FA Recommendations}

On the other hand, recommendation data was obtained from two sort of data, the recommendations of individual analysts jointly with their corresponding dates and the consensus recommendations. This information were not available in all the detail required for all companies selected and this is the reason why some of the original companies had been removed from the sample. So, the companies finally analyzed have been 18 pharmaceuticals and 2 biotechnological companies. All of these information have been obtained from I/B/E/S. As each house of analysis has a different category in its recommendations, $\mathrm{I} / \mathrm{B} / \mathrm{E} / \mathrm{S}$ has turned all the data to a single category with 5 different levels, assigning to each one a numerical value: (1) strong buy, (2) buy, (3) hold, (4) under-perform and (5) sell.

In Figure 1 we can see the total number of individual recommendations for each company. In general they are biased to positive recommendations founding very few selling recommendations, although this can be sensible to the period considered. For example, in the case of Novartis, there are more recommendations with values 2 (buy) and 3 (hold) (Figure 2).

It is interesting to know if the arrival of new recommendations to the market has some effect in prices and so on in returns. In a first graphical analysis, we can see in Figures 4 and 5 each individual recommendation over prices, returns, variance and volume for Novartis. Dashed green color with a star represents the case of a recommendation improvement respect to the previous, in solid red if it is worse and in dotted black if it is equal.

5 TAQ are the initials of The Trade and Quote, it is an intra-day database with the operations of the companies in the New York Stock Exchange (NYSE), American Stock Exchange (AMEX)), Nasdaq National Market System (NMS) and SmallCaps.NYSE companies. 
About consensus recommendations, once $\mathrm{I} / \mathrm{B} / \mathrm{E} / \mathrm{S}$ has assigned a numerical value to each analyst calculates the consensus recommendation, being this one the mean on a monthly basis of the assigned values. In Figure 3 we can see the for Novartis the prices over the different percentages of buy, sell and hold consensus recommendations for all the time period between 2001 and 2005. As can be seen, quotations go down or up more or less at the same time than the percentage of buy or sell recommendations vary.

We encoded the values of the recommendations to move in the range -2 to 2. This five values corresponds to: strong sell $(-2)$, sell $(-1)$, hold (0), buy (1) and strong buy (2). We have made some new variables in order to test the effect of the recommendations on stock returns. These new variables are the following:

- Recommendation: Dummy variable indicating if this day a new analyst recommendation has been published. If this is the case, then it could imply higher volatility in the stock, since this new information will require the market to react.

- Value: Value of the new recommendation. The five possible values correspond to: strong sell (-2), sell (-1), hold (0), buy (1) and strong buy (2). It will take into account if the sense of the recommendation has a differential effect on returns (i.e. reactions are stronger after selling recommendations).

- Absolute_value: Absolute value of the new recommendation. It makes no differences between sell or buy orders, just the intensity of the recommendation (buy/sell, 1 or strong buy/strong sell, 2). This variable tries to capture the sensitivity of strong recommendations.

- Variation: It is the change in the value of the recommendation of the analyst with respect to his previous recommendation value. This variable takes into account that the effect on the market will be different if an analyst changes from buy to sell or viceversa, or if he publishes a new recommendation but maintains it as buy or sell.

- $N_{-}$analysts: Number of analysts that follows a company. This variable changes along the sample and proxies the power of a given analyst. If very few analysts track a given company, the recommendation given by one of them has greater impact than would have had if he just was one more of a pretty crowd.

- Consensus: Daily mean of the last recommendations made by each analyst. It represents the mean of the analysts feelings about the company. The higher the value of this variable, the higher the recommendations to buy and viceversa.

- Consensus_change: Difference of the Consensus with respect to previous day. It takes into account that the importance could be not in the value of the recommendations given, but on the changes produced.

- Absolute_consensus_change: Absolute value of Consensus_change. The importance is given in this variable to the intensity of the change in consensus 
and not to the sense of the movement.

- Agreement: Standard deviation of the recommendations on the Consensus. A value 0 means that all analysts agree in the recommendations, and an increase in this variable indicates a higher degree of disagreement. The lower the value of this variable would imply less uncertainty about the company and lower volatility in the stock.

- Agreement_change: Differences in the value of variable Agreement from previous day. It indicates a momentum of increasing or decreasing uncertainty.

- Absolute_agreement_change: The absolute value of previous variable Agreement_change. It gives the intensity in the increase or reduction on uncertainty never mind the sense of this movement.

These variables have been defined for all the companies in the sample of section 2 . With the data on stock returns and recommendations we can define a model that relates both set of variables.

\section{Reference model}

Normality hypothesis is usually rejected in the context of financial asset returns. Since the works of Mandelbrot (1963) and Fama (1965), three characteristics are highlighted to diverge from a gaussian distribution.

(1) Extreme values in the distribution. The tails of the distributions concentrate more probability than is supposed on a Gaussian distribution.

(2) Extreme movements are more frequent in the left side of the distribution, as a consequence of market's higher sensibility to bad news.

(3) Clusters of volatility. Days with high volatility tends to be followed by high volatility also in next days.

The first feature leads to a leptokurtic distribution, while the second one to the presence of skewness in the distribution. This abnormalities are usually attributed to outliers that are distributed as fat tails. This fact can be due to corrections in the normal activity of the market or due to crashes.

As an example, in Figure 6 we can see a graphical description for Novartis (NVS). In the first line of graphs we have the plot of prices and returns. In the second line, the histogram with the estimated normal distribution that will show us if the distribution of the returns has fat tails as well as the squared returns as an indicator of volatility. In third line, the variance of the returns is plotted by hours and by days. As can be seen, there is greater volatility in the first hours than at the end of the day, and with variance by days we can identify those dates where is more probably that news appear. Finally, in the last line we can see the mean of the volume by hours and by days. With this 
graphs we can see that more volume is registered at the beginning and at the end of the day.

The descriptive statistics show asymmetric and leptokurtic distributions in all cases. As can be seen in Table 3, skewness coefficients are mostly negative and kurtosis values are greater than 3 in all cases. Most companies present high values of standard deviations which means that these companies could present more extreme values than in a normal distribution. The skewness coefficients are negative in most of the cases and kurtosis coefficients are all greater than 3. Both are evidences of non-gaussian distributions, a fact confirmed by JarqueBera test, presenting pvalues close to zero for all the companies, rejecting the null of normality.

Moreover, in financial returns we can observe persistence in volatility and volatility clustering, mean reverting.

The study of the autocorrelation function for Novartis shows, weak evidence of dependence on the mean (Figure 7), assuming a constant mean. At the same time, in the correlogram of the squared returns (Figure 8) all the autocorrelation coefficients are positive and with significant and slow positive decay which indicates an important dependence of past values of the volatility.

Observations of this type in financial time series have led, in many cases, to the use of $\mathrm{ARCH}$ family models in financial forecasting and derivatives pricing, such as ARCH (Engle, 1982) and GARCH (Bollerslev, 1986) models. The main idea behind these widely-used models is that volatility is dependent upon past realizations of the asset process and related volatility process. This is a more precise formulation of the intuition that asset volatility tends to revert to some mean rather than remaining constant or moving in monotonic fashion over time.

\subsection{Regime Switching Model}

Previously to the analysis of recommendation impact on stock returns, we need a benchmark model for the later variable. Financial returns are usually modeled using stochastic volatility models like GARCH family of Engle (1982) and Bollerslev (1986). Although this models allows to take into account volatility clustering they are not fully able to explain fat tails and skewness. Some modifications on this models could help to introduce such features in the model but had the drawback of their increasing complexity.

Alternative modeling of return distribution via Extreme Values Theory ${ }^{6}$ has

$\overline{6}$ See Embrechts et al. (1997) for a detailed description. 
similar disadvantages and becomes difficult to conciliate them with financial theory. Nevertheless a simplest way of reaching similar results are the mixture of normal distributions, each one representing a different situation of the market.

We can find the origin of this model in the work of Clark (1973), that uses the concept of subordinated stochastic process and interpreted the leptokurtic behavior as a signal that the negotiation activity is not distributed uniformly during the period of negotiation.

Another important work that applied a mixture of normals to explain the indicated problems (fat tails, kurtosis and asymmetry) is the one of Kon (1984). He proposed a mixture of normal discrete distributions and indicated that although the hypothesis of a model with stationary normal distribution is empirically rejected, the gaussian hypothesis has great importance in financial theory.

The model presented by Kon (1984) was formed by a discrete mixture of four normal distributions for stock-exchange returns of 30 shares quoting in the Dow Jones. His results showed that it was a superior model than the student alternative, allowing to explain the asymmetry and kurtosis observed in the analyzed data. Gonzalez and Gimeno (2006) also showed that with a mixture of just two normal distribution it is possible to explain leptokurtosis and skewness of 30 worldwide stock indexes.

Nevertheless a mixture of normal distribution is not able to explain the cluster of volatility in stock returns. In this sense, Schwert (1989) consider a model with two normal distributions with different variance in which transitions between variances are governed by a two-state Markov process. Turner et al. (1989) generalized the model to allow both mean and variance to change between regimes, capturing the skewness in the distribution with different impacts on mean returns of states of low or high volatility. Finally, Hamilton and Susmel (1994) showed that a Markov regime switching (MRS) model provides a better statistical fitting than $\mathrm{ARCH}$ models.

This MRS model, originally proposed by Hamilton (1989), would allow us to distinguish the existence of different regimes in financial assets. Although MRS models can be quite flexible in the mean equation of each regime, we have selected a restricted version with a constant similar to Turner et al. (1989),

$$
r_{t}=\left\{\begin{array}{lll}
\mu_{1}+\epsilon_{1 t} & \text { if } s_{t}=1 \quad \epsilon_{1 t} \sim N\left(0, \sigma_{1}\right) \\
\mu_{2}+\epsilon_{2 t} & \text { if } s_{t}=2 \quad \epsilon_{2 t} \sim N\left(0, \sigma_{2}\right)
\end{array}\right.
$$

Model 1 has two different regimes $\left(s_{t}=1\right.$ and $\left.s_{t}=2\right)$, one of them with low 
volatility $\left(\sigma_{1}\right)$ and other one with high volatility $\left(\sigma_{2}\right)$ that could be linked to the turmoil after the entrance of new information on the market. Skewness would be consequence of different means $\left(\mu_{1}\right.$ and $\left.\mu_{2}\right)$ between regimes, since markets tends to react stronger upon bad news.

Each of the regimes in equation 1 are normally distributed, so the model can be considered as a mixture of normal distributions. Additionally, state variable $\left(s_{t}\right)$ is a Markov chain with a transition matrix $P$ (equation 2) that gives the probabilities of being in any regime conditioned to the regime in previous period.

$$
P=\left(p_{i j}\right)=\left(\begin{array}{ll}
p_{11} & p_{12} \\
p_{21} & p_{22}
\end{array}\right)=\left(\begin{array}{cc}
p_{11} & 1-p_{11} \\
1-p_{22} & p_{22}
\end{array}\right)
$$

In equation $2, p_{11}$ denotes the probability of being in regime $1\left(s_{t}=1\right)$, conditioned to having been also in regime 1 the day before $\left(P\left(s_{t}=1 \mid s_{t-1}=\right.\right.$ $1)$ ), whereas $p_{22}$ plays the same role for the second regime. Values of $p_{22}$, linked to the regime of high volatility, close to one will implied volatility persistence and produce clusters of volatility as the ones found in financial time series.

Parameter estimations of both equations 1 and 2 are obtained via maximum likelihood (see Hamilton (1989)). Nevertheless, the function we have to optimize is not linear, being sensible to the initial parameters in the model. To accelerate the optimization process we select initial values for the parameters $\left(\mu_{1}, \mu_{2}, \sigma_{1}, \sigma_{2}, p_{11}, p_{22}\right.$ and the probability of being on regime 1 in the first period $p_{0}$ ), following the methodology of Gonzalez and Gimeno (2006).

We roughly identify the days of high volatility to compute both $\mu_{i}$ and $\sigma_{i}$ in each regime. The methodology consist in an iterative procedure that successively test normality hypothesis though Jarque-Bera test (Jarque and Bera, 1980) and drop the data with higher absolute daily returns, until a sub-sample is reached where normality hypothesis is not rejected. The returns in this subsample are initially considered as generated by the distribution with lower volatility of regime 1 , whereas the dropped ones would be identified as days with high volatility.

Through this procedure we will obtain two groups of returns, that can be assigned to regime 1 and 2. Once we have separate the data, we can obtain the initial mean and variance values for each of the states. Transition matrix is also easily estimated once we have tentative regimes for each day, whereas $p_{0}$ is set to be equal to 0 or 1 depending on the first return classification.

This values are just tentative, and final parameters are estimated via maximum likelihood. Final results are presented in Table 4. As can be seen, regime 2 
is assigned to the distribution with higher standard deviation (almost three times higher in mean). The probability of remaining in the same regime of previous period are also high in both states, and reinforce the evidence on clusters of volatility. Figure 9 represents the stock returns of Novartis plotted with different color depending on the results of the probabilities of being in each regime. It is possible to see how the probabilities of being in the first regime (in green color) or in the second one (in red color with star points) change along the time and coincide with the periods of high and low volatility in the returns.

In Table 5 we present the results of likelihood ratio tests ${ }^{7}$ on the estimated model for each company. The test on the null hypothesis of equal means in both regimes (column 2) are accepted in all but two companies, as well as being equal to zero (columns 4,5 and 6) in all but one case. This results imply that there is no forecasting opportunity on stock returns, as is generally found in the financial literature. Nevertheless, in the case of $\sigma_{i}$ parameters, the null hypothesis is rejected (column 3), reinforcing the idea of the two regimes to be related with low and high volatility. Finally, and related with the previous result, the null of no regime switching is also rejected in all cases (column 7).

Once we have obtained the results for the tests mentioned, we have proceed to calculate the standardized residuals of the model. When we compare the moments of the original return distribution with the ones obtained from the residuals of the MRS model, as can be seen in Table 6, both skewness and leptokurtosis are dramatically reduced ( $80 \%-90 \%$ of reduction) in all the companies considered. In terms of normality, the reduction is even higher in the Jarque-Bera statistic, and in half of the cases the reduction is enough to accept the normality hypothesis.

In Figures 10 and 11 we present the correlation and partial correlation function for both the residuals of the MRS model as well as the squared residuals. When compared with the ones obtained from the raw returns (Figures 7 and 8) it is possible to see that although correlogram on the original variables are quite similar, in the case of the squared variables, that in the case of returns indicates the presence of conditional heterokedasticity, this evidence disappear in the residuals of the MRS model, indicating that GARCH modelling is no longer needed. Similar results are obtained for the other companies.

7 See Engle (1984) for a general description and Hansen (1992) for its application on MRS models. 


\section{The effect of FA recommendations}

Once we have a valid model to represent stock returns, we can measure the impact on volatility of FA recommendations. We follow Schaller and van Norden (1997), and consider that the transition probabilities on equation 2, instead of being constant, can be set to be a function of some exogenous variables,

$$
\begin{aligned}
& p_{11}=P\left(S_{t}=1 / s_{t-1}=1, A_{t}\right)=\Phi\left(A_{t} \beta_{1}\right) \\
& p_{22}=P\left(S_{t}=2 / s_{t-1}=2, A_{t}\right)=\Phi\left(A_{t} \beta_{2}\right)
\end{aligned}
$$

where $A_{t}$ is, in our case, a vector containing the recommendation variables defined in section 2.3 (Schaller and van Norden (1997) used the past price/dividend ratio)and $\Phi(\cdot)$ is a function that returns the cumulative probability of a normal distribution. Then the probabilities on (3), becomes Probit models ${ }^{8}$, and the transition matrix is redefined,

$$
P=\left(\begin{array}{cc}
\Phi\left(A_{t} \beta_{1}\right) & 1-\Phi\left(A_{t} \beta_{1}\right) \\
1-\Phi\left(A_{t} \beta_{2}\right) & \Phi\left(A_{t} \beta_{2}\right)
\end{array}\right)
$$

Since $A_{t}$ vector contains eleven variables, $\beta$ vectors would add 22 extra parameters to the estimation. In Table 7, we present the LR test under the null of no effect of FA recommendations in the volatility regime. As can be seen, in all of the cases the null is rejected, and strong evidence is found of the effect of FA on the volatility. This result suggest that either the FA has direct effect on the market or that he has reach in its recommendation the same conclusion the market does.

\section{Conclusions}

In the present paper we have analyzed the effect of FA recommendations on the market volatility of Pharmaceutical and Biotechnological companies. This paper contributes to the literature because analyzes the sector and its stock exchange characteristics. Moreover, we study the impact of de Financial Analysts recommendations on volatility instead of the traditional literature that focuses on prices.

We have found in all of the 20 companies analyzed strong evidence of corre-

8 In fact, we used Probit estimations as initial values of the final model. 
lation between FA recommendations and changes in volatilities. This result may point out to the role of FA to extend new information about a company to the market, since such event is usually linked to higher volatility in a price discovery process.

We have also found that a mixture of simple two normal distributions with the same mean but different variance, with probabilities governed by a Markov chain (MRS model), is able to capture the main features of financial assets in a meaningful model. A MRS model is considerably more parsimonious than alternatives like GARCH models and extreme values distributions, but at the same time is able to take into account volatility clustering, leptokurtosis and skewness in financial returns.

\section{References}

Berndt, E., 2002. Pharmaceuticals in U.S. Health Care: Determinants of Quantitiy and Price. Journal of Economic Perspectives 16, 45-66.

Bollerslev, T., 1986. Generalized autoregressive conditional heteroskedaticity. Journal of Econometrics 31, 307-327.

Castanias, R. P., 1979. Macroinformation and the variability of stock market prices. Journal of Finance 34, 439-450.

Clark, P. K., 1973. A subordinated stochastic process model with finite variance for speculative prices. Econometrica 41, 135-156.

Danzon, P. M., Chao, L. W., 2000. Does regulation drive out competition in pharmaceutical markets. Journal of Law \& Economics 23, 311-357.

DiMasi, J. A., Hansen, R. W., Grabowski, H. G., 2003. The price of innovation: new estimates of drug development costs. Journal of Health Economics, 151185.

DiMasi, J. A., Hansen, R. W., Grabowski, H. G., Lasagna, L., 1991. Cost of innovation in the pharmaceutical industry. Journal of Health Economics, $107-142$.

Ederington, L. H., Lee, J. H., 1993. How markets process information: New releases and volatility. The Journal of Finance 48 (4), 1161-1191.

Embrechts, P., Klüppelberg, C., Mikosch, T., 1997. Modelling Extremal Events. Springer Verlag, Berlin.

Engle, R. F., 1982. Autoregressive conditional heteroscedasticity with estimates of the variance of united kingdom inflation. Econometrica 50, 9871006.

Engle, R. F., 1984. Handbook of Econometrics. Vol. II. Elsevier Science Publishers BV, Amsterdam, Ch. Wald, likelihood ratio, and Lagrange Multiplier Tests in Econometrics, pp. 775-826.

Fama, E. F., 1965. The behavior of stock market prices. Journal of Business $38,34-105$. 
Fama, E. F., Fisher, L., Jensen, M., Roll, R., 1969. The adjustment of stock prices to new information. International Economic Review 10, 1-21.

Gonzalez, C. I., Gimeno, R., Mayo 2006. Evaluación de las metodología para medir el valor en riesgo. Estabilidad Financiera (Banco de España) 11, 4559.

Grabowski, H., Vernon, J., 1990. A new look at the returns and risks to pharmaceutical R \& D. Management Science 36, 804-821.

Grabowski, H., Vernon, J., 2002. Effective patent life in pharmaceuticals. International Journal of Technology Management 19, 98-120.

Hamilton, J. D., 1989. A new approach to the economic analysis of nonstationary time series and the business cycle. Econometrica 57, 357-84.

Hamilton, J. D., 1990. Analysis of time series subject to changes in regime. Journal of Econometrics 45, 39-70.

Hamilton, J. D., Susmel, R., 1994. Autoregressive conditional heteroskedasticity and changes in regime. Journal of Econometrics 64 (1-2), 307-333.

Hansen, B. E., 1992. The Likelihood Ratio Test Under Nonstandard Conditions: Testing the Markov Switching Model of GNP. Journal of Applied Econometrics 7, S61-S82.

Jarque, C. M., Bera, A. K., 1980. Efficient tests for normality, homoscedasticity and serial independence of regression residuals. Economics Letters 6, 255259.

Kon, S. J., 1984. Models of Stock Returns. A comparison. Journal of Finance 39 (1), 147-165.

Mandelbrot, B., 1963. The variation of certain speculative prices. Journal of Business 36 (4), 394-419.

Pearce, D. K., Roley, V. V., 1985. Stock prices and economic news. The Journal of Business 58 (1), 49-67.

Philipson, T. J., 2002. The regulation of medical innovation and pharmaceutical markets. Journal of Law and Economics 45, 583-585.

Schaller, H., van Norden, S., 1997. Regime switching in stock market returns. Applied Financial Economics 7, 177-191.

Schwert, G., 1989. Why does stock volatility change over time? Journal of Finance 44 (5), 1115-1153.

Standard \& Poor's, 2004. Industry surveys. healthcare: Pharmaceuticals.

Turner, C. M., Startz, R., Nelson, C. R., 1989. A markov model of heteroskedasticity, risk, and learning in the stock market. Journal of Financial Economics 25, 3-22.

Womack, K. L., 1996. Do brokerage analysts' recommendations have investment value? The Journal of Finance 51 (1), 137-167. 
Figure 1. Total number of recommendations by company (2001-2005)

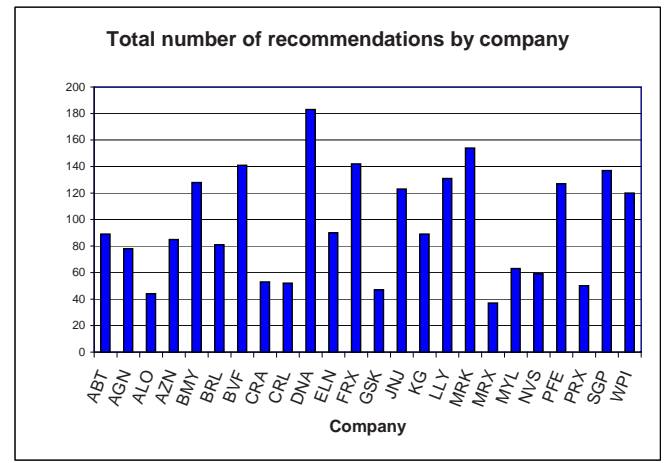

Figure 2. Histogram of total recommendations (2001-2005)
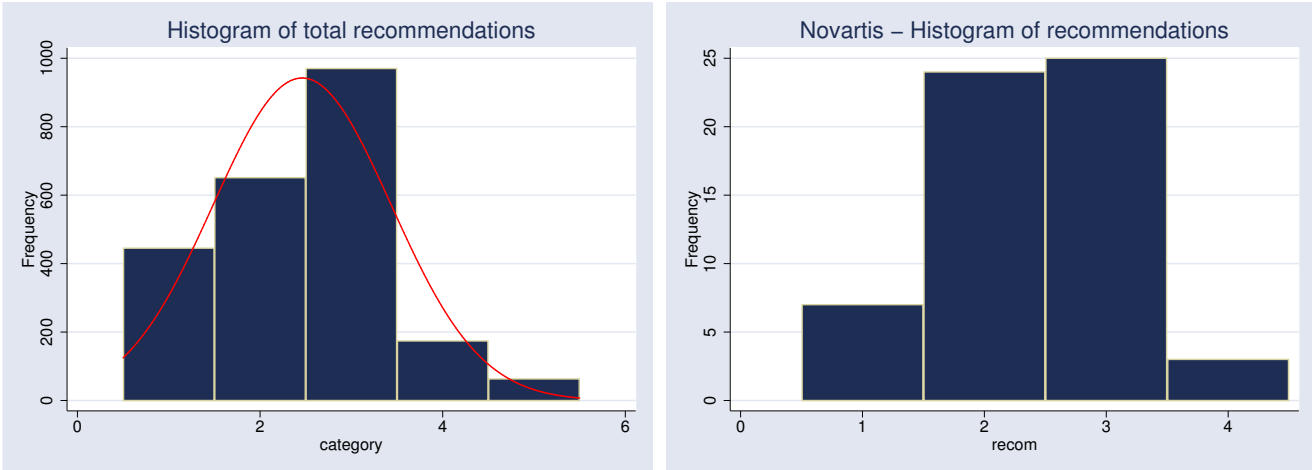

Figure 3. NVS prices and percentages of consensus recommendations (2001-2005)

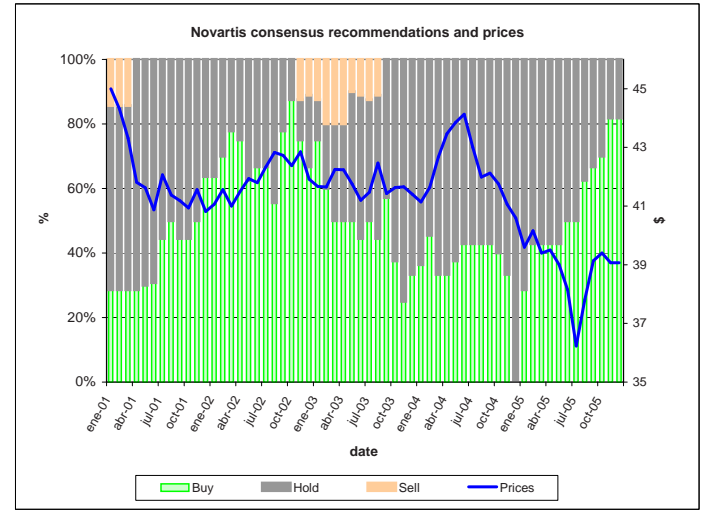


Figure 4. NVS Individual recommendations over prices and returns
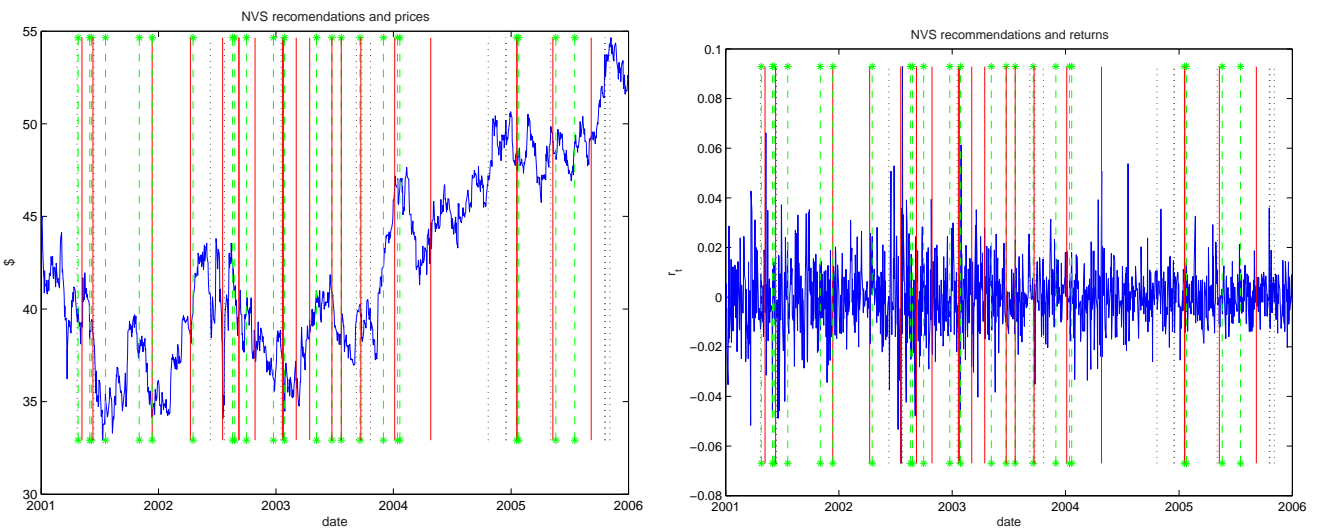

Figure 5. NVS Individual recommendations over variance and volume
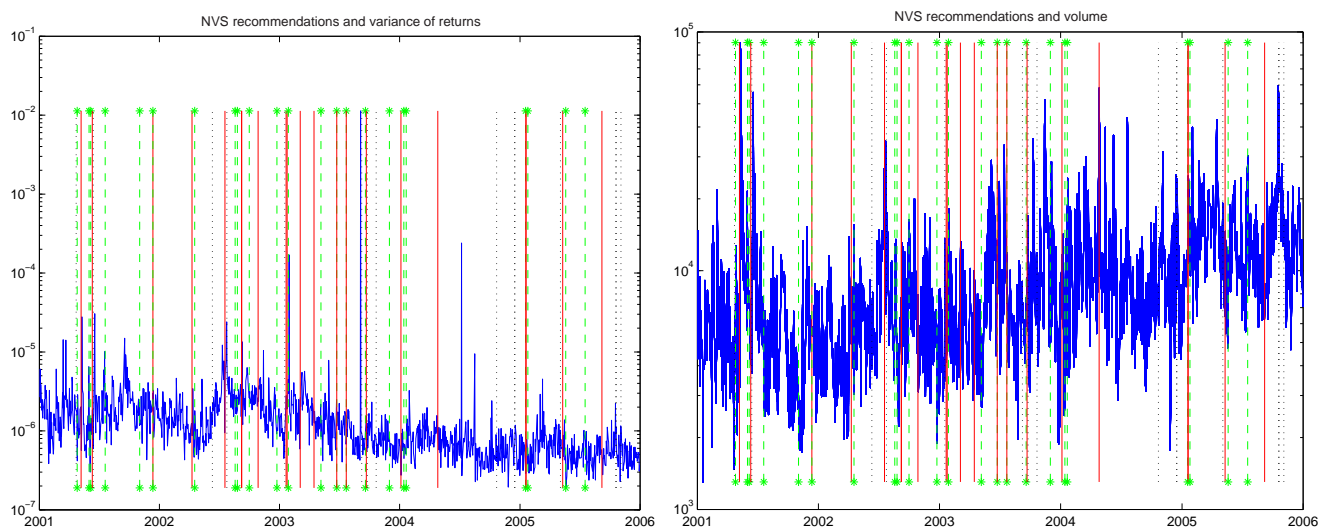

Table 1

Top ten companies in the NYSE Health Care Index

\begin{tabular}{|l|r|}
\hline Company & Weight \\
\hline Pfizer Inc. & $10.00 \%$ \\
Johnson \& Johnson & $9.73 \%$ \\
GlaxoSmithKline PLC & $8.59 \%$ \\
Novartis AG & $6.82 \%$ \\
Sanofi-Aventis & $5.06 \%$ \\
AstraZeneca PLC & $4.97 \%$ \\
Merck \& Co. Inc. & $4.70 \%$ \\
Abbott Laboratories & $3.81 \%$ \\
Wyeth & $3.39 \%$ \\
UnitedHealth Group Inc. & $3.35 \%$ \\
\hline
\end{tabular}

Source: NYSE Stock Exchange 
Figure 6. Graphical description
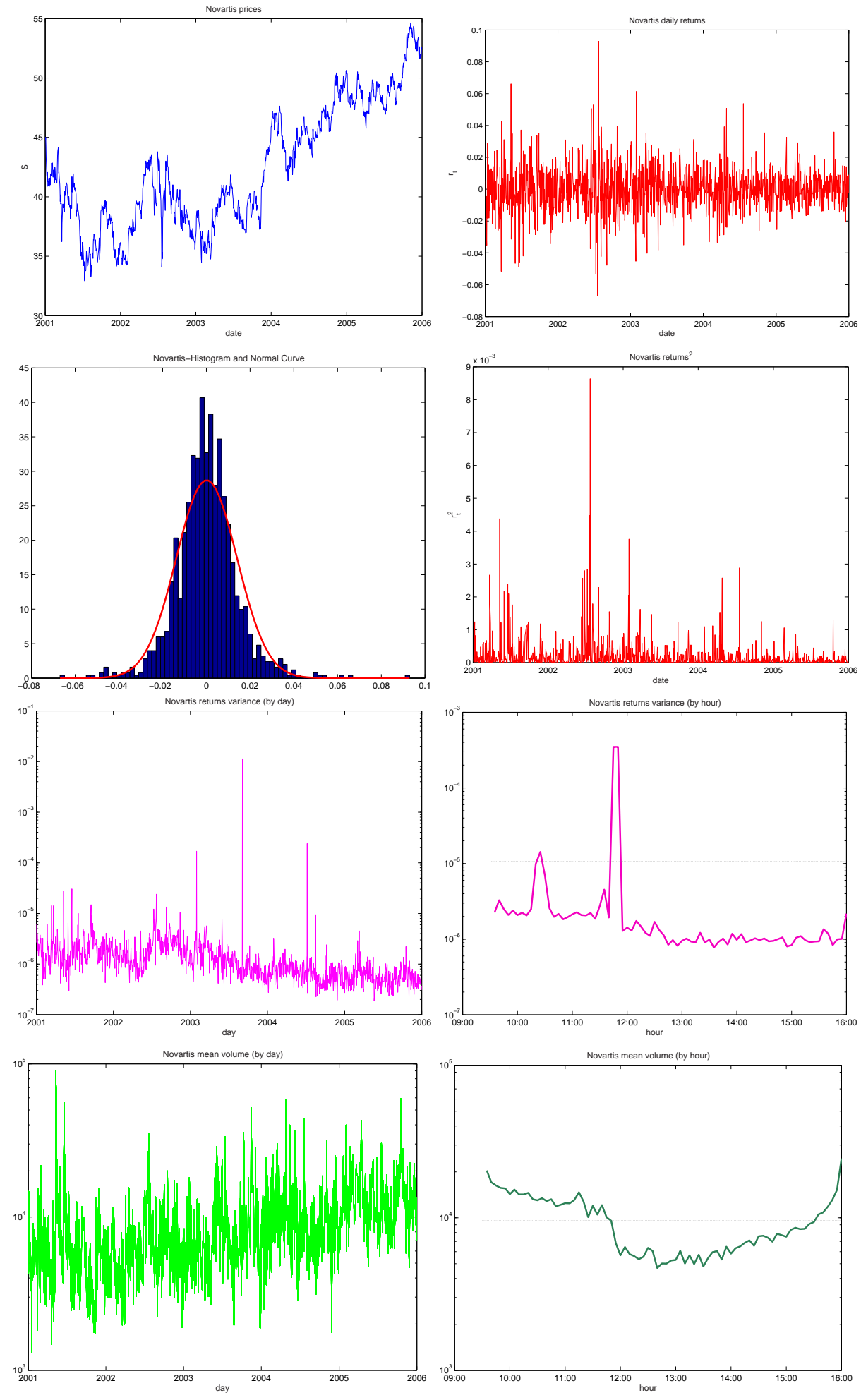
Figure 7. NVS Autocorrelation function for returns
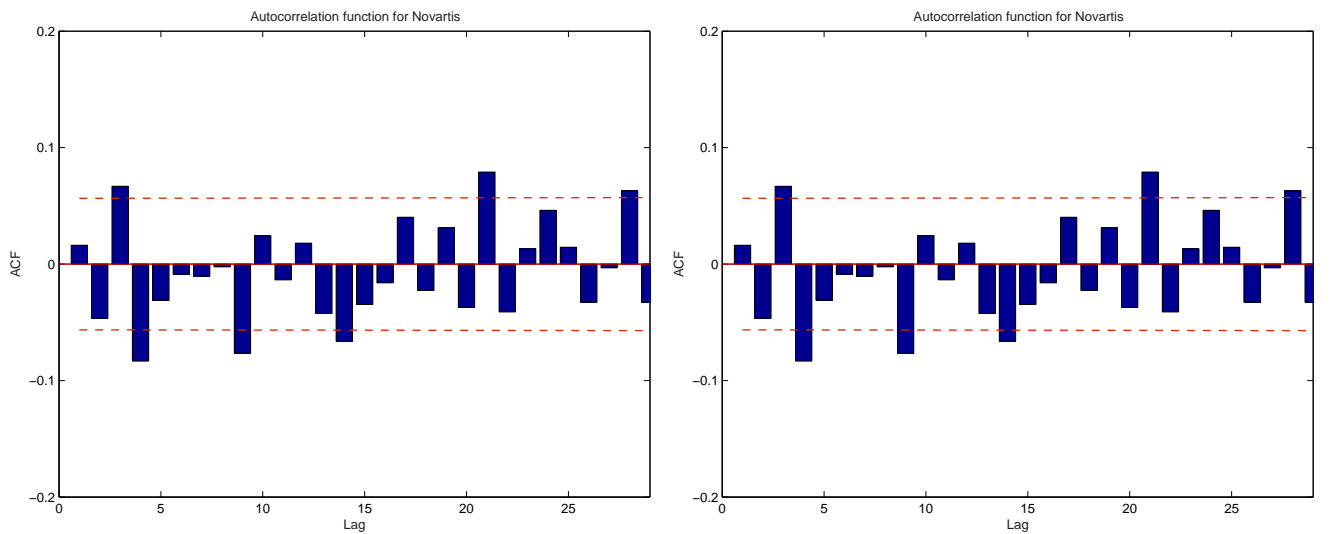

Figure 8. NVS Autocorrelation function for squared returns
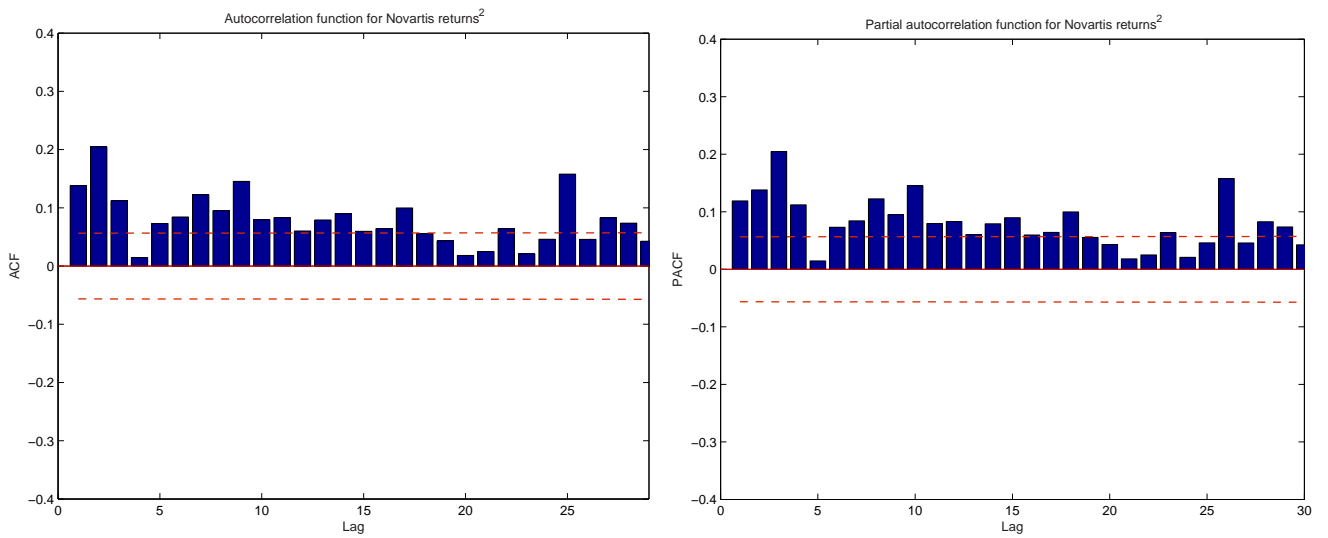

Figure 9. NVS Posteriori probabilities for returns

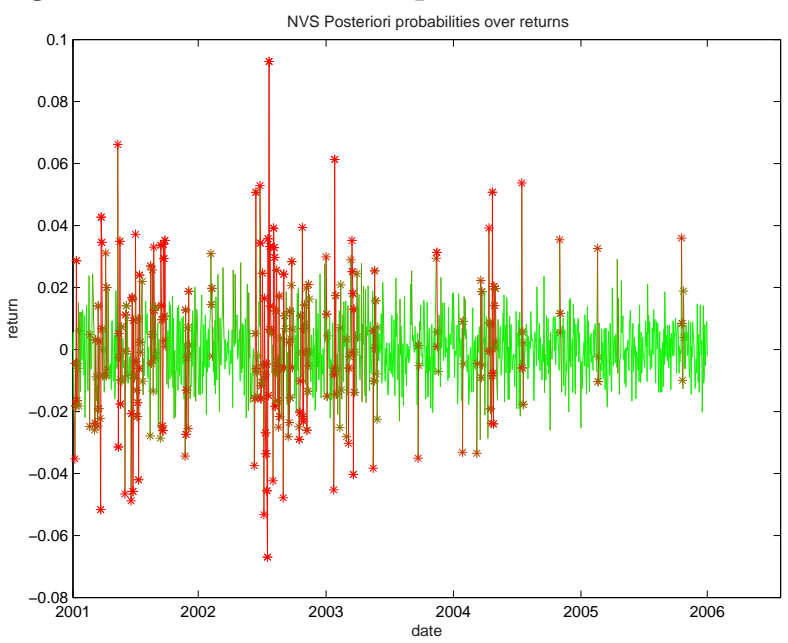


Figure 10. NVS Autocorrelation function for standardized RMS resids
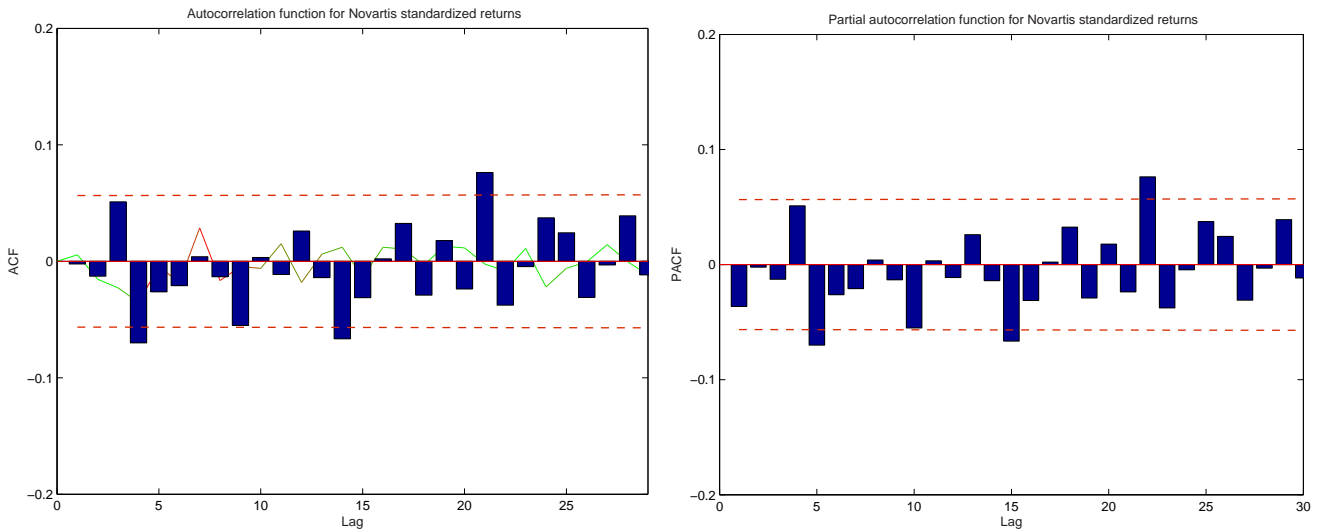

Figure 11. NVS Autocorrelation function for squared standardized RMS resids
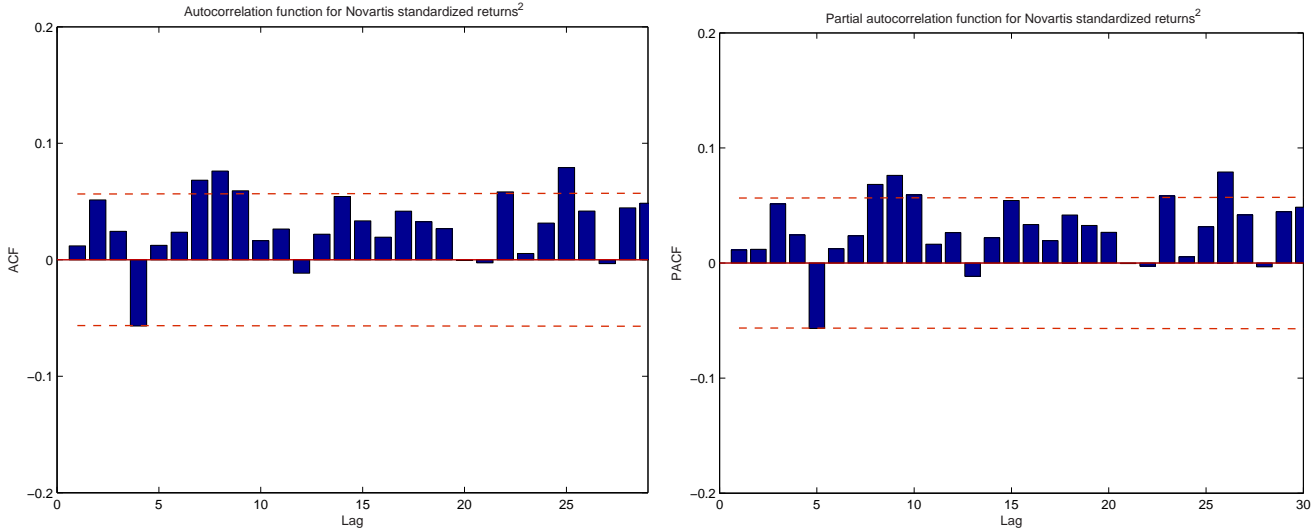
Table 2

Companies analyzed

\begin{tabular}{ll}
\hline Pharmaceuticals & $(\mathrm{ABT})$ \\
\hline Abbott Laboratories & $(\mathrm{AGN})$ \\
Allergan Inc. & $(\mathrm{ALO})$ \\
Alpharma Inc. & $(\mathrm{AZN})$ \\
AstraZeneca Group plc & $(\mathrm{BRL})$ \\
Pharmaceuticals, Inc. & $(\mathrm{BVF})$ \\
Biovail Corporation & $(\mathrm{BMY})$ \\
Bristol Myers Squibb Co. & $(\mathrm{LLY})$ \\
Eli Lilly and Company & $(\mathrm{FRX})$ \\
FOREST LABS INC & $(\mathrm{GSK})$ \\
GlaxoSmithKline & $(\mathrm{JNJ})$ \\
Johnson \& Johnson. & $(\mathrm{KG})$ \\
King Pharmaceuticals Inc. & $(\mathrm{MRX})$ \\
Medicis Pharmaceutical Corp. & $(\mathrm{MRK})$ \\
Merck \& Co Inc. & $(\mathrm{MYL})$ \\
Mylan Laboratories Inc. & $(\mathrm{NVS})$ \\
Novartis & $(\mathrm{PFE})$ \\
Pfizer Inc. & $(\mathrm{PRX})$ \\
Pharmaceutical Resources, Inc. & $(\mathrm{SGP})$ \\
Schering Plough Corporation & $(\mathrm{WPI})$ \\
Watson Pharmaceuticals Inc. & \\
\hline Biotechnologicals & $(\mathrm{CRA})$ \\
\hline Applera-Celera Genomics & $(\mathrm{CRL})$ \\
Charles River Laboratories International, Inc. & $(\mathrm{DNA})$ \\
Genentech, Inc &
\end{tabular}


Table 3

Descriptive statistics

\begin{tabular}{|r|r|r|r|r|r|r|r|r|}
\hline & mean & var & std & CV & skew & kurt & JB & pvalue \\
\hline ABT & $-0.02 \%$ & $0.03 \%$ & $1.74 \%$ & 107.62 & -0.78 & 14.42 & 6918.98 & 0 \\
AGN & $0.01 \%$ & $0.03 \%$ & $1.85 \%$ & 155.82 & -0.11 & 6.10 & 501.41 & 0 \\
ALO & $-0.03 \%$ & $0.13 \%$ & $3.63 \%$ & 118.19 & -0.16 & 31.45 & 42144.44 & 0 \\
AZN & $0.00 \%$ & $0.03 \%$ & $1.84 \%$ & 511.39 & -0.50 & 13.27 & 5536.40 & 0 \\
BMY & $-0.09 \%$ & $0.03 \%$ & $1.85 \%$ & 20.53 & -1.32 & 13.29 & 5865.08 & 0 \\
BRL & $0.05 \%$ & $0.05 \%$ & $2.23 \%$ & 41.41 & -0.19 & 5.86 & 430.71 & 0 \\
BVF & $-0.03 \%$ & $0.10 \%$ & $3.15 \%$ & 91.72 & -0.59 & 12.26 & 4537.17 & 0 \\
CRA & $-0.09 \%$ & $0.11 \%$ & $3.29 \%$ & 36.13 & 0.38 & 5.19 & 278.01 & 0 \\
CRL & $0.04 \%$ & $0.05 \%$ & $2.34 \%$ & 60.83 & -0.49 & 9.68 & 2370.59 & 0 \\
DNA & $0.07 \%$ & $0.09 \%$ & $2.99 \%$ & 43.36 & 1.80 & 28.06 & 33387.48 & 0 \\
FRX & $0.02 \%$ & $0.05 \%$ & $2.19 \%$ & 115.26 & -0.37 & 7.63 & 1139.93 & 0 \\
GSK & $-0.01 \%$ & $0.02 \%$ & $1.57 \%$ & 193.56 & -0.04 & 5.46 & 314.49 & 0 \\
JNJ & $0.01 \%$ & $0.02 \%$ & $1.39 \%$ & 105.74 & -1.41 & 25.25 & 26186.05 & 0 \\
KG & $-0.06 \%$ & $0.09 \%$ & $3.00 \%$ & 47.42 & -0.94 & 15.88 & 8816.23 & 0 \\
LLY & $-0.04 \%$ & $0.03 \%$ & $1.65 \%$ & 43.24 & 0.03 & 5.11 & 231.41 & 0 \\
MRK & $-0.09 \%$ & $0.04 \%$ & $1.96 \%$ & 22.87 & -3.44 & 56.30 & 150400.91 & 0 \\
MRX & $0.01 \%$ & $0.05 \%$ & $2.13 \%$ & 207.67 & 0.07 & 6.52 & 644.12 & 0 \\
MYL & $0.05 \%$ & $0.04 \%$ & $2.10 \%$ & 44.22 & -0.54 & 11.00 & 3394.20 & 0 \\
NVS & $0.01 \%$ & $0.02 \%$ & $1.39 \%$ & 109.34 & 0.28 & 6.66 & 713.72 & 0 \\
PFE & $-0.05 \%$ & $0.03 \%$ & $1.74 \%$ & 32.11 & -0.36 & 7.25 & 963.80 & 0 \\
PRX & $0.12 \%$ & $0.12 \%$ & $3.42 \%$ & 27.66 & -1.08 & 28.40 & 33827.26 & 0 \\
SGP & $-0.08 \%$ & $0.04 \%$ & $2.10 \%$ & 27.59 & -0.78 & 7.77 & 1306.10 & 0 \\
WPI & $-0.03 \%$ & $0.06 \%$ & $2.53 \%$ & 80.16 & -6.24 & 126.74 & 805521.77 & 0 \\
\hline
\end{tabular}


Table 4

Estimated values of MRS parameters

\begin{tabular}{|l|rr|rr|rrr|}
\hline & $\mu_{1}$ & $\sigma_{1}$ & $\mu_{2}$ & $\sigma_{2}$ & $p_{01}$ & $p_{11}$ & $p_{22}$ \\
\hline ABT & $0.01 \%$ & $1.14 \%$ & $-0.07 \%$ & $2.77 \%$ & 1.00 & 0.97 & 0.92 \\
ALO & $0.05 \%$ & $2.32 \%$ & $-0.57 \%$ & $11.70 \%$ & 1.00 & 0.96 & 0.36 \\
AGN & $0.03 \%$ & $1.02 \%$ & $0.02 \%$ & $2.68 \%$ & 0.00 & 0.94 & 0.90 \\
AZN & $-0.03 \%$ & $1.30 \%$ & $0.15 \%$ & $3.25 \%$ & 1.00 & 0.97 & 0.89 \\
BMY & $-0.01 \%$ & $1.04 \%$ & $-0.20 \%$ & $2.62 \%$ & 0.00 & 0.98 & 0.96 \\
BRL & $0.07 \%$ & $1.40 \%$ & $0.03 \%$ & $3.17 \%$ & 1.00 & 0.93 & 0.83 \\
BVF & $0.08 \%$ & $1.94 \%$ & $-0.47 \%$ & $5.87 \%$ & 0.00 & 0.92 & 0.67 \\
CRA & $-0.10 \%$ & $2.29 \%$ & $-0.12 \%$ & $4.21 \%$ & 0.00 & 0.99 & 0.98 \\
DNA & $0.06 \%$ & $1.76 \%$ & $0.22 \%$ & $4.94 \%$ & 1.00 & 0.97 & 0.92 \\
FRX & $0.06 \%$ & $1.51 \%$ & $-0.10 \%$ & $3.71 \%$ & 0.00 & 0.92 & 0.71 \\
GSK & $-0.01 \%$ & $1.12 \%$ & $0.00 \%$ & $2.36 \%$ & 1.00 & 0.98 & 0.95 \\
JNJ & $0.01 \%$ & $0.87 \%$ & $0.04 \%$ & $2.21 \%$ & 0.00 & 0.96 & 0.89 \\
KG & $0.10 \%$ & $1.67 \%$ & $-0.49 \%$ & $5.20 \%$ & 0.00 & 0.91 & 0.74 \\
LLY & $-0.05 \%$ & $1.20 \%$ & $0.04 \%$ & $2.47 \%$ & 0.00 & 0.98 & 0.95 \\
MRK & $0.02 \%$ & $1.24 \%$ & $-0.73 \%$ & $4.44 \%$ & 0.00 & 0.96 & 0.68 \\
MYL & $0.01 \%$ & $1.34 \%$ & $0.21 \%$ & $3.56 \%$ & 0.00 & 0.90 & 0.67 \\
NVS & $0.01 \%$ & $0.99 \%$ & $0.07 \%$ & $2.24 \%$ & 1.00 & 0.97 & 0.88 \\
PFE & $-0.06 \%$ & $1.21 \%$ & $-0.01 \%$ & $2.82 \%$ & 0.00 & 0.98 & 0.93 \\
SGP & $-0.01 \%$ & $1.42 \%$ & $-0.20 \%$ & $3.01 \%$ & 0.00 & 0.97 & 0.94 \\
WPI & $0.01 \%$ & $1.52 \%$ & $-0.80 \%$ & $7.72 \%$ & 0.00 & 0.96 & 0.46 \\
\hline
\end{tabular}


Table 5

LR tests on MRS models

\begin{tabular}{|c|c|c|c|c|c|c|c|c|}
\hline & $\mu_{1}=\mu_{2}$ & \multicolumn{2}{|c|}{$\sigma_{1}=\sigma_{2}$} & $\mu_{1}=0$ & $\mu_{2}=0$ & \multirow{2}{*}{$\begin{array}{l}\mu_{1}=\mu_{2}=0 \\
0.220\end{array}$} & \multicolumn{2}{|c|}{$s_{t}(1)=s_{t}(2)$} \\
\hline $\mathrm{ABT}$ & 0.216 & 287.466 & $* * *$ & 0.047 & 0.192 & & 287.515 & *** \\
\hline AGN & 0.002 & 295.462 & $* * *$ & 0.414 & 0.025 & 0.482 & 303.659 & *** \\
\hline $\mathrm{ALO}$ & 0.167 & 345.210 & $* * *$ & 0.529 & 0.141 & 0.625 & 587.771 & $* * *$ \\
\hline AZN & 0.611 & 263.053 & $* * *$ & 0.407 & 0.474 & 0.786 & 263.053 & *** \\
\hline BMY & 2.065 & 228.716 & $* * *$ & 0.061 & 2.637 & 2.760 & 369.720 & *** \\
\hline BRL & 0.044 & 157.160 & $* * *$ & 1.264 & 0.017 & 1.524 & 157.375 & $* * *$ \\
\hline $\mathrm{BVF}$ & 1.630 & 200.014 & $* * *$ & 1.128 & 1.331 & 2.001 & 357.511 & $* * *$ \\
\hline CRA & 0.004 & 156.733 & $* * *$ & 1.325 & 0.345 & 1.807 & 157.837 & *** \\
\hline DNA & 0.313 & 418.513 & $* * *$ & 0.754 & 0.611 & 1.508 & 419.714 & $* * *$ \\
\hline FRX & 0.343 & 160.138 & $* * *$ & 1.162 & 0.153 & 1.168 & 197.755 & $* * *$ \\
\hline GSK & 0.003 & 204.682 & $* * *$ & 0.021 & 0.000 & 0.021 & 204.682 & *** \\
\hline JNJ & 0.042 & 303.724 & $* * *$ & 0.165 & 0.108 & 0.337 & 303.987 & *** \\
\hline KG & 3.175 & 240.580 & $* * *$ & 2.261 & 2.466 & 4.013 & 417.837 & *** \\
\hline LLY & 0.312 & 181.891 & $* * *$ & 1.430 & 0.061 & 1.434 & 183.322 & $* * *$ \\
\hline MRK & 3.641 & 265.081 & $* * *$ & 0.183 & 3.603 & 3.641 & 497.709 & $* * *$ \\
\hline MYL & 0.187 & 131.424 & $* * *$ & 0.014 & 0.344 & 0.950 & 245.092 & *** \\
\hline NVS & 0.128 & 124.210 & $* * *$ & 0.089 & 0.211 & 0.376 & 190.653 & $* * *$ \\
\hline PFE & 0.066 & 258.339 & $* * *$ & 1.893 & 0.004 & 1.941 & 258.612 & $* * *$ \\
\hline SGP & 1.321 & 199.900 & $* * *$ & 0.009 & 1.720 & 1.803 & 201.089 & $* * *$ \\
\hline WPI & 0.828 & 241.755 & $* * *$ & 0.070 & 0.814 & 0.842 & 707.335 & $* * *$ \\
\hline
\end{tabular}

With $* * *$ for those values with pvalue $<0.01$, with $* *$ for pvalue $<0.05$ and $*$ for pvalue $<0.1$ 
Table 6

Normality test

\begin{tabular}{|r|rr|rr|rr|rr|}
\hline & \multicolumn{2}{|c|}{ SKEWNESS } & \multicolumn{2}{|c|}{ KURTOSIS } & \multicolumn{3}{|c|}{ JARQUE-BERA TEST } \\
\hline & r1 & rs & r1 & rs & r1 & rs \\
\hline ABT & -0.78 & -0.19 & 14.42 & 4.08 & 6918.98 & $* * *$ & 68.44 & $* * *$ \\
AGN & -0.11 & 0.00 & 6.10 & 2.70 & 501.41 & $* * *$ & 4.82 & $*$ \\
ALO & -0.16 & 0.02 & 31.45 & 2.75 & 42144.44 & $* * *$ & 3.40 & \\
AZN & -0.50 & -0.16 & 13.27 & 3.38 & 5536.40 & $* * *$ & 12.53 & $* * *$ \\
BMY & -1.32 & -0.37 & 13.29 & 4.89 & 5865.08 & $* * *$ & 214.49 & $* * *$ \\
BRL & -0.19 & 0.00 & 5.86 & 2.64 & 430.71 & $* * *$ & 6.75 & $* *$ \\
BVF & -0.59 & 0.09 & 12.26 & 2.78 & 4537.17 & $* * *$ & 4.28 & \\
CRA & 0.38 & 0.20 & 5.19 & 3.20 & 278.01 & $* * *$ & 10.68 & $* * *$ \\
DNA & 1.80 & 0.37 & 28.06 & 5.74 & 33387.48 & $* * *$ & 418.85 & $* * *$ \\
FRX & -0.37 & -0.03 & 7.63 & 2.59 & 1139.93 & $* * *$ & 9.27 & $* * *$ \\
GSK & -0.04 & -0.03 & 5.46 & 2.81 & 314.49 & $* * *$ & 2.16 & \\
JNJ & -1.41 & -0.36 & 25.25 & 6.09 & 26186.05 & $* * *$ & 524.72 & $* * *$ \\
KG & -0.94 & -0.08 & 15.88 & 3.44 & 8816.23 & $* * *$ & 11.18 & $* * *$ \\
LLY & 0.03 & -0.08 & 5.11 & 2.56 & 231.41 & $* * *$ & 11.38 & $* * *$ \\
MRK & -3.44 & -0.12 & 56.30 & 4.24 & 150400.91 & $* * *$ & 82.85 & $* * *$ \\
MYL & -0.54 & -0.19 & 11.00 & 3.11 & 3394.20 & $* * *$ & 7.96 & $* *$ \\
NVS & 0.28 & 0.05 & 6.66 & 2.74 & 713.72 & $* * *$ & 4.10 & \\
PFE & -0.36 & -0.07 & 7.25 & 2.88 & 963.80 & $* * *$ & 1.88 & \\
SGP & -0.78 & -0.20 & 7.77 & 3.37 & 1306.10 & $* * *$ & 15.09 & $* * *$ \\
WPI & -6.24 & -0.12 & 126.74 & 3.84 & 805521.77 & $* * *$ & 39.23 & $* * *$ \\
\hline
\end{tabular}

With $* * *$ for those values with pvalue $<0.01$, with $* *$ for pvalue $<0.05$ and $*$ for pvalue $<0.1$

$r_{1}$ represents stock returns while $r_{s}$ are MRS standardized resids 
Table 7

LR tests on the influence of FA over transition probabilities

\begin{tabular}{|r|rr|}
\hline & \multicolumn{2}{|c|}{ FA rec } \\
\hline ABT & 64.321 & $* * *$ \\
AGN & 89.747 & $* * *$ \\
ALO & 63.090 & $* * *$ \\
AZN & 44.512 & $* * *$ \\
BMY & 84.160 & $* * *$ \\
BRL & 79.139 & $* * *$ \\
BVF & 117.595 & $* * *$ \\
CRA & 57.173 & $* * *$ \\
DNA & 73.213 & $* * *$ \\
FRX & 81.531 & $* * *$ \\
GSK & 42.240 & $* * *$ \\
JNJ & 62.860 & $* * *$ \\
KG & 82.656 & $* * *$ \\
LLY & 53.203 & $* * *$ \\
MRK & 39.542 & $* *$ \\
MYL & 70.134 & $* * *$ \\
NVS & 48.862 & $* * *$ \\
PFE & 43.515 & $* * *$ \\
SGP & 56.298 & $* * *$ \\
WPI & 64.971 & $* * *$ \\
\hline
\end{tabular}

Where

$* * *$ indicates pvalue $<0.01$,

$* *$ for pvalue $<0.05$

and $*$ for pvalue $<0.1$ 